\title{
PRODUTIVIDADE E CARACTERÍSTICAS FÍSICAS DE FRUTOS DE Passiflora edulis ENXERTADO SOBRE Passiflora gibertii EM DIFERENTES ESPAÇAMENTOS DE PLANTIO ${ }^{1}$
}

\author{
JOSÉ CARLOS CAVICHIOLI ${ }^{2}$, FRANCISCO SEIITI KASAI ${ }^{2}$ MAURICIO DOMINGUEZ NASSER ${ }^{2}$
}

RESUMO - O objetivo deste trabalho foi avaliar o efeito de diferentes espaçamentos de plantio na produtividade e nas características físicas de frutos do maracujazeiro-amarelo (Passiflora edulis Sims) enxertado sobre o maracujazeiro-de-veado (Passiflora gibertii N.E. Brown). O experimento foi conduzido no município de Adamantina-SP, no período de maio de 2009 a abril de 2010, adotando-se o delineamento em blocos ao acaso, com seis tratamentos e quatro repetições. Os tratamentos constituíram-se de diferentes espaçamentos na linha de plantio: T1 - 1,0 m (3.125 plantas/ha); T2 - 1,5 m (2.083 plantas/ha); T3 - 2,0 m (1.563 plantas/ha); T4 - 3,0 m (1.042 plantas/ha); T5 - 4,0 m (781 plantas/ha), e T6 - 5,0 m (625 plantas/ha). $\mathrm{O}$ espaçamento nas entrelinhas foi de 3,2 $\mathrm{m}$ de largura em todos os tratamentos. Avaliaram-se o diâmetro transversal dos frutos, o número de frutos por planta, a massa média por fruto e a produtividade. Verificou-se que o adensamento de plantas não interferiu no diâmetro transversal e na massa média dos frutos. Observouse um menor número de frutos por planta nos espaçamentos mais adensados, que foram compensados pela produtividade por área.

Termos para indexação: densidade de plantas, maracujá, enxertia.

\section{PRODUCTIVITY AND PHYSICAL CHARACTERISTICS OF FRUITS OF Passiflora edulis GRAFTED Passiflora gibertii IN DIFFERENT PLANTING DENSITIES}

\begin{abstract}
The objective of work was to evaluate the productivity and physical characteristics of fruits of yellow passion fruit (Passiflora edulis Sims) grafted on Passiflora gibertii in different planting densities. The experiment was carried in Adamantina, SP, Brazil, from May 2009 to April 2010, adopting the experimental design in randomized, with six treatments and four replicates. The treatments were different planting spacing: T1 - $1.0 \mathrm{~m}$ (3.125 plants/ha); T2 - $1.5 \mathrm{~m}$ (2.083 plants/ha); T3 - $2.0 \mathrm{~m}$ (1.563 plants/ha); T4 - $3.0 \mathrm{~m}$ (1.042 plants/ha); T5 - $4.0 \mathrm{~m}$ (781 plants/ha); T6 - $5.0 \mathrm{~m}$ (625 plants/ha). The distance between the lines was 3.2 $\mathrm{m}$ for all the treatments. The variables evaluated were: diameter of fruits, number of fruits, weight of fruits and productivity. The planting density did not favor diameter and weight of fruits. It was observed a smaller number of fruits in smaller spacings, which were compensated by productivity.

Index terms: planting densities, yellow passion fruit, grafting.
\end{abstract}

\section{INTRODUÇÃO}

O Brasil destaca-se como o principal produtor mundial de maracujá, entretanto, nos últimos anos, tem-se observado a redução da produtividade devido à ocorrência de problemas fitossanitários que aumentaram com a expansão da cultura. A morte prematura de plantas, provocada pela associação de fungos de solo, nematoides e bactéria, tem-se constituído em um dos principais problemas para a cultura no Brasil.
Uma das alternativas para o controle desse problema é a utilização de porta-enxertos resistentes (CHAVES et al., 2004; SILVA et al., 2005; CAVICHIOLI et al., 2009). Várias espécies de passifloras nativas vêm apresentando resistência a essas doenças (CHAVES et al., 2004), destacando-se entre elas o Passiflora gibertii (RONCATTO et al., 2004; CAVICHIOLI et al., 2009).

Conforme Forshey e Elfving (1977), a produção é função da densidade de plantio, densidade de flores, índice de pegamento de frutos e tamanho

${ }^{1}$ (Trabalho 238-13). Recebido em: 03-07-2013. Aceito para publicção em: 13-01-2014.

${ }^{2}$ Pesquisador da APTA Regional Alta Paulista, Caixa Postal 191, 17.800-000, Adamantina (SP), fone: (18) 3521-4800. E-mail: jccvichioli@apta.sp.gov.br 
dos frutos. Plantas enxertadas têm desenvolvimento diferente de plantas pé-franco (CAVICHIOLI et al., 2011). Assim, a densidade de plantas na linha de plantio do maracujazeiro-amarelo enxertado é um importante fator a ser considerado em um sistema de produção, podendo interferir na eficiência técnica e econômica de uma cultura. De acordo com Andrade Júnior et al. (2003), o adensamento de plantio em maracujazeiro pé-franco permite maior produtividade nas primeiras safras, porém a produtividade deve ser acompanhada de maior retorno econômico. Nasser et al. (2011) verificaram que o adensamento de plantio não favoreceu o desenvolvimento de maracujazeiroamarelo enxertado sobre maracujazeiro-doce.

Considerando que o uso da enxertia, visando ao controle da morte prematura de plantas, tem apresentado resultados satisfatórios no cultivo do maracujazeiro.Objetivou-se, neste trabalho, avaliar a produtividade em diferentes densidades de plantio do maracujazeiro-amarelo enxertado sobre o maracujazeiro-de-veado.

\section{MATERIAL E MÉTODOS}

O experimento foi conduzido em uma propriedade localizada a $387 \mathrm{~m}$ de altitude, $21^{\circ} 40^{\prime} \mathrm{S}$ de latitude e $51^{\circ} 07^{\prime} \mathrm{W}$ de longitude, no município de Adamantina, na região da Nova Alta Paulista, no período de maio de 2009 a abril de 2010. O solo da área experimental foi classificado como Argissolo Vermelho-Amarelo, eutrófico, A moderado, textura arenosa/média e topografia ondulada.

O clima da região é Cwa, segundo a classificação de Koppen, com estação chuvosa no verão e estação seca no inverno. A precipitação média anual é de $1.300 \mathrm{~mm}$. A temperatura média anual está em torno de $22-23^{\circ} \mathrm{C}$; a do mês mais quente é em torno de $26^{\circ} \mathrm{C}$; a do mês mais frio está por volta de $17-18^{\circ} \mathrm{C}$ (CAVICHIOLI et al., 2009).

$\mathrm{O}$ experimento foi instalado de acordo com o delineamento estatístico em blocos ao acaso, com seis tratamentos e quatro repetições. Os tratamentos constituíram-se de diferentes espaçamentos na linha de plantio: T1-1,0 m (3.125 plantas/ha); T2-1,5 m (2.083 plantas/ha); T3-2,0 m (1.563 plantas/ha); T43,0 m (1.042 plantas/ha); T5-4,0 m (781 plantas/ha), e T6-5,0 m (625 plantas/ha)

Utilizou-se de plantas de maracujazeiroamarelo (Passiflora edulis Sims), cultivar Sul Brasil, enxertadas sobre o maracujazeiro-de-veado (Passiflora gibertii N.E. Brown). As sementes de $P$. gibertii foram embebidas em água por cerca de doze horas e, posteriormente, semeadas em tubetes de 19 $\mathrm{cm} \times 5,5 \mathrm{~cm}$, contendo substrato comercial Bioplant ${ }^{\circledR}$.
Da mesma forma, foram produzidas as plântulas de maracujazeiro-amarelo para o fornecimento dos garfos. A semeadura do $P$. gibertii foi realizada no dia 12 de dezembro de 2009; e do $P$. edulis, quinze dias depois.

A enxertia foi realizada 30 dias após a emergência das plantas, quando os porta-enxertos e enxertos atingiram cerca de 6 a $8 \mathrm{~cm}$ de altura e uma a duas folhas definitivas, utilizando-se do método de enxertia por garfagem tipo fenda cheia.

O plantio das mudas no campo foi realizado no dia 05 de maio de 2009, aproximadamente 90 dias após a enxertia. $\mathrm{O}$ espaçamento da cultura foi de 3,2 entre ruas e variou de 1,0 a 5,0 m entre plantas. As plantas foram conduzidas com um único ramo vegetativo (ramo primário) até atingir o segundo fio de arame, sendo que as brotações laterais foram eliminadas.

Foram avaliadas as seguintes características: diâmetro transversal dos frutos, realizada com auxílio de um paquímetro de precisão de $0,1 \mathrm{~mm}$; número de frutos, realizado pela contagem dos frutos após cada colheita; massa média dos frutos, obtida tomando-se a massa de frutos sadios em cada colheita dividida pelo número de frutos e produtividade. Após cada colheita, que foi realizada, em média, a cada três dias, os frutos foram pesados em balança de precisão de $1 \mathrm{~g}$, calculando-se a produtividade em $\mathrm{kg} \cdot \mathrm{ha}^{-1}$. Foi avaliada a produtividade no período de novembro de 2009 a abril de 2010, em pomar de primeiro ano.

A análise estatística dos dados incluiu a análise de variância com a realização do teste F. Quando significativo, efetuou-se a análise de regressão, ao nível de 5\% de probabilidade, também pelo teste $\mathrm{F}$.

\section{RESULTADOS E DISCUSSÃO}

Houve uma resposta quadrática para a média do número de frutos por planta (Figura 1). Os dados de produção indicaram que o maior número de frutos por planta foi obtido nos espaçamentos maiores, onde o ponto de máxima eficiência foi obtido com o uso do espaçamento de 3,8 m entre plantas, diferindo dos espaçamentos mais adensados (1,0 e 2,0 $\mathrm{m}$ nas entrelinhas). No espaçamento de $1,0 \mathrm{~m}, \mathrm{o}$ número de frutos por planta foi de 20,24 , enquanto no espaçamento de 5,0 $\mathrm{m}$ foi de 39,26 frutos por planta. O menor número de frutos nos espaçamentos mais adensados pode estar relacionado com o menor número de flores, causado pelo autossombreamento das plantas.

Através da interpretação dos dados da análise de variância e da análise de regressão, constatou-se 
que não houve diferenças para diâmetro transversal de frutos e para as massas médias de fruto nos diferentes espaçamentos adotados (Tabela 1). $\mathrm{O}$ diâmetro transversal de frutos variou de 7,74 cm no espaçamento de $3,2 \times 1,5 \mathrm{~m}$ a $8,15 \mathrm{~cm}$ no espaçamento de 3,2 x 3,0 m. Esses valores ficaram próximos ao encontrado por Cavichioli et al. (2011), que foi de $8,07 \mathrm{~cm}$.

Os valores para as massas médias de fruto variaram de $127,77 \mathrm{~g}$ no espaçamento de 3,2 x 4,0 $\mathrm{m}$ a 200,53 g no espaçamento de 3,2 x 2,0 m (Tabela 01). Estes resultados concordam com os de Ritzinger et al. (1987) e Andrade Júnior et al. (2003).

Para a produtividade (Figura 2), observase uma resposta linear decrescente em função dos espaçamentos entre as linhas adotados. A maior produtividade foi obtida no espaçamento mais adensado (3,2 x 1,0 m), com $14.551 \mathrm{~kg}$, diferindo do maior espaçamento $(3,2 \times 5,0 \mathrm{~m})$, que foi de 4.322 $\mathrm{kg}$. Esses resultados foram inferiores aos obtidos por Cavichioli et al. (2011), quando obtiveram a média de 30,89 t/ha em plantas de maracujazeiroamarelo enxertadas sobre maracujazeiro-de-veado, no espaçamento de 3,2 x 5,0 m. Essa diferença observada deveu-se à infecção das plantas pelo vírus do endurecimento dos frutos, causado pelo CABMV (Cowpea aphid-borne mosaic vírus), doença que se encontra disseminada na maioria das regiões produtoras, reduzindo a produção, já que os frutos ficam menores, deformados e endurecidos.

A produtividade foi influenciada pelas diferentes densidades de plantio, o que concorda com o resultado obtido por Ritzinger et al. (1987). Assim, o menor número de frutos por planta, obtido no espaçamento mais adensado, foi compensado pelo maior número de plantas por área. De acordo com Andrade Júnior et al. (2003), no plantio adensado, a área foliar não aumenta, proporcionalmente, em relação ao número de plantas, e o sombreamento dos ramos resulta em uma diminuição da área foliar que serve de fonte, e aumenta a área foliar que serve de dreno. Portanto, existe uma relação entre a área foliar disponível (fonte) e o número de frutos de uma planta, que está diretamente relacionado com o tamanho e o peso dos frutos (FORSHEY; ELFVING, 1977).

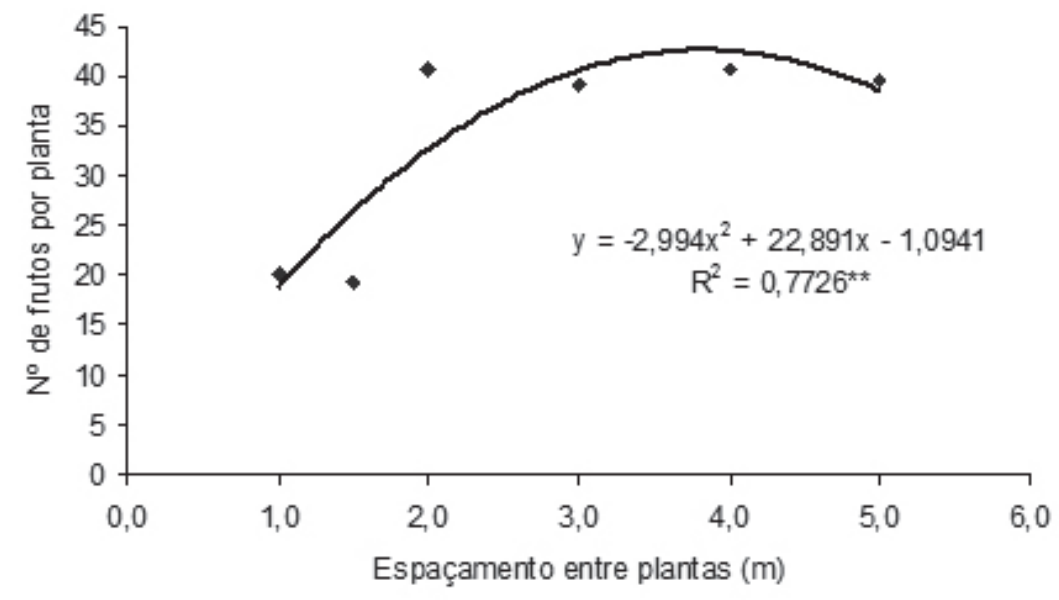

FIGURA 1 - Número de frutos por planta de maracujazeiro-amarelo enxertado sobre maracujazeiro-de-veado e submetida a diferentes densidades de plantio. Adamantina-SP 


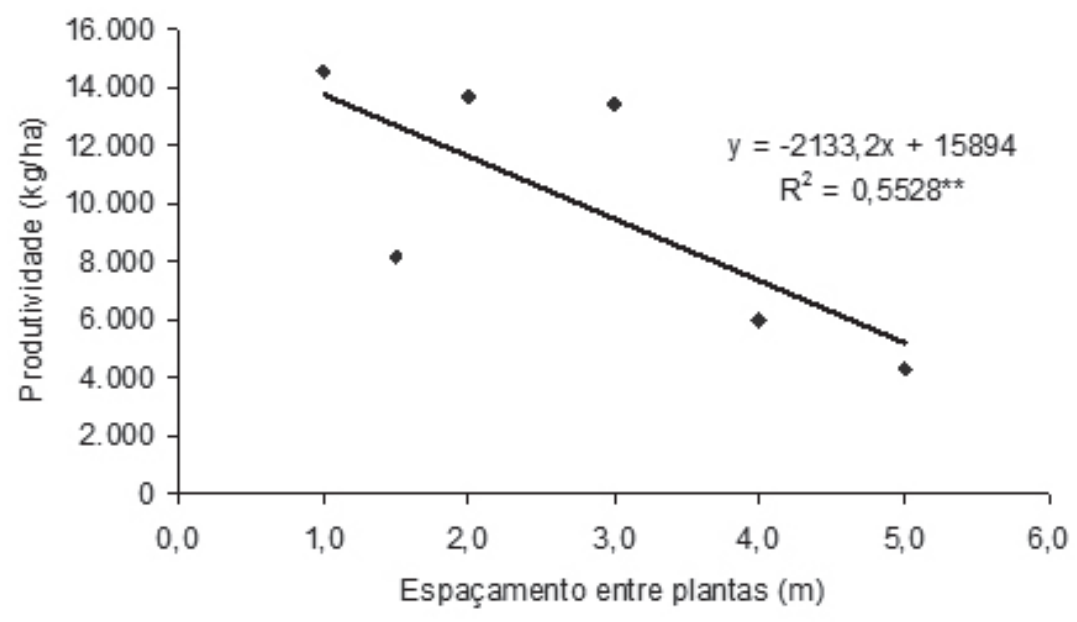

FIGURA 2 - Produtividade de maracujazeiro-amarelo enxertado sobre maracujazeiro-de-veado e submetido a diferentes densidades de plantio. Adamantina-SP, 2009-2010.

TABELA 1 - Diâmetro transversal de frutos e massa média por fruto de maracujazeiro-amarelo enxertado sobre maracujazeiro-de-veado e submetido a diferentes densidades de plantio. AdamantinaSP, $2009-2010$.

\begin{tabular}{cccc}
\hline $\begin{array}{c}\text { Espaçamento }(\mathrm{m}) \\
\text { linha x planta }\end{array}$ & Plantas/ha & $\begin{array}{c}\text { Diâmetro } \\
\text { transversal de } \\
\text { frutos }(\mathrm{cm})\end{array}$ & $\begin{array}{c}\text { Massa média por } \\
\text { fruto }(\mathrm{g})\end{array}$ \\
\hline $3,2 \times 1,0$ & 3.125 & 8,10 & 187,02 \\
$3,2 \times 1,5$ & 2.083 & 7,74 & 188,32 \\
$3,2 \times 2,0$ & 1.563 & 8,15 & 200,53 \\
$3,2 \times 3,0$ & 1.042 & 7,83 & 192,67 \\
$3,2 \times 4,0$ & 781 & 8,13 & 127,77 \\
$3,2 \times 5,0$ & 625 & 7,91 & 201,03 \\
\hline F & & $1,10 \mathrm{~ns}$ & $0,97 \mathrm{~ns}$ \\
CV (\%) & & 4,10 & 11,72 \\
\hline
\end{tabular}

ns - não significativo, pelo teste $\mathrm{F}$, ao nível de $5 \%$ de probabilidade.

\section{CONCLUSÕES}

1-O adensamento de plantas não interfere no diâmetro transversal e na massa média dos frutos de maracujazeiro-amarelo enxertado sobre maracujazeiro-de-veado.

2-O menor número de frutos por planta observado nos espaçamentos mais adensados foi compensado pela maior produtividade por área.

\section{REFERÊNCIAS}

ANDRADE JÚNIOR, V.C. de; ARAÚJO NETO, S.E. de; RUFINI, J.C.M.; RAMOS, J.D. Produção de maracujazeiro-amarelo sob diferentes densidades de plantio. Pesquisa Agropecuária Brasileira, Brasília, v.38, n.12, p.1.381-1.386, 2003.

CAVICHIOLI, J.C.; CORRÊA, L. de S.; BOLIANI, A.C.; OLIVEIRA, J.C. de. Uso de câmara úmida em enxertia hipocotiledonar de maracujazeiro-amarelo sobre três porta-enxertos. Revista Brasileira de Fruticultura, Jaboticabal, v.31, n.2, p.532-538, 2009. 
CAVICHIOLI, J.C.; CORRÊA, L. S.; BOLIANI,A.C.; SANTOS, P.C. Desenvolvimento e produtividade do maracujazeiro-amarelo enxertado em três portaenxertos. Revista Brasileira de Fruticultura, Jaboticabal, v.33, n.2, p.558-566, 2011.

CHAVES, R.C.; JUNQUEIRA, N.T.V.; MANICA, I.; PEIXOTO, J.R.; PEREIRA, A.V.; FIALHO, J.F. Enxertia de maracujazeiro-azedo em estacas herbáceas enraizadas de espécies de passifloras nativas. Revista Brasileira de Fruticultura, Jaboticabal, v.26, n.1, p.120-123, 2004.

FORSHEY, C.G.; ELFVING, D.C. Fruit numbers, fruit size and yield relationships in 'McIntosh' apples. Journal of the American Society for Horticultural Science, Mount Vernon, v.102, n.4, p.399-402,1977.

NASSER, M.D.; CAVICHIOLI, J.C.; KASAI, F.S.; VITORINO, R. Desenvolvimento de maracujazeiroamarelo enxertado sobre maracujazeiro-doce em diferentes espaçamentos de plantio. Revista Brasileira de Fruticultura, Jaboticabal, p. 638-642, 2011. Volume especial.
RITZINGER, R.; MANICA, I.; RIBOLDI, J. Efeito do espaçamento de plantio sobre a produção do maracujá-amarelo em Viamão-RS. Pesquisa Agropecuária Brasileira, Brasília, v.22, n.8, p.809825, 1987.

RONCATTO, G.; OLIVEIRA, J.C.de R.C.; NOGUEIRA FILHO, G.C.; CENTURION, M.A.P.da C.; FERREIRA, F.R. Comportamento de maracujazeiros (Passiflora spp.) quanto à morte prematura. Revista Brasileira de Fruticultura, Jaboticabal, v.26, n.3, p.552-554, 2004.

SILVA, F.M.; CORRÊA, L.de S.; BOLIANI, A.C.; SANTOS, P.C. dos. Enxertia de mesa de Passiflora edulis Sims f. flavicarpa Deg. sobre Passiflora alata Curtis, em ambiente de nebulização intermitente. Revista Brasileira de Fruticultura, Jaboticabal, v.27, n.1, p.98-101, 2005. 